\title{
Procedure Indication
}

National Cancer Institute

\section{Source}

National Cancer Institute. Procedure Indication. NCI Thesaurus. Code C117517.

The condition, disease or disorder that the procedure is intended to investigate or address. 